\title{
Correction to: Influence of protein (human galectin-3) design on aspects of lectin activity
}

\author{
Gabriel García Caballero ${ }^{1}$ - Donella Beckwith ${ }^{2}$. Nadezhda V. Shilova ${ }^{3,4} \cdot$ Adele Gabba $^{5}$ - Tanja J. Kutzner ${ }^{1}$. \\ Anna-Kristin Ludwig ${ }^{1} \cdot$ Joachim C. Manning ${ }^{1} \cdot$ Herbert Kaltner $^{1} \cdot$ Fred Sinowatz $^{6} \cdot$ Mare Cudic $^{2} \cdot$ Nicolai V. Bovin $^{3,7}$. \\ Paul V. Murphy ${ }^{5} \cdot$ Hans-Joachim Gabius ${ }^{1}$
}

Published online: 9 June 2020

(c) The Author(s) 2020

\section{Correction to: Histochemistry and Cell Biology https://doi.org/10.1007/s00418-020-01859-9}

In the original publication of the article, the "Result" section has been published with an error. The lines "...(Fig. 8a, e for free Lac, Fig. 8c, g for compound 1 and insets to Fig. 8a, e for compound 2). This is also symbolized by adding the category of semiquantitative intensity assessment..." have been misplaced in the "Discussion" section.

The sentences 5 and 6 "At $0.01 \mathrm{mM}$ Lac in all cases, control values were obtained (Fig. 8a, e for free Lac, Fig. 8c, $\mathrm{g}$ for compound 1 and insets to Fig. 8a, e for compound 2). This is also symbolized by adding the category of semiquantitative intensity assessment to the figures". have now been placed in order in the paragraph starting with the sentence "In addition to probing the characteristics..." of the Results

The original article can be found online at https://doi.org/10.1007/ s00418-020-01859-9.

Mare Cudic

mcudic@fau.edu

$\triangle$ Nicolai V. Bovin

professorbovin@yandex.ru

Paul V. Murphy

paul.v.murphy@nuigalway.ie

$\triangle$ Hans-Joachim Gabius

gabius@tiph.vetmed.uni-muenchen.de; gabius@lectins.de

1 Institut für Physiologische Chemie, Tierärztliche Fakultät, Ludwig-Maximilians-Universität München, 80539 München, Germany

2 Department of Chemistry and Biochemistry, Florida Atlantic University, Boca Raton, FL 33431, USA

3 Shemyakin-Ovchinnikov Institute of Bioorganic Chemistry, Russian Academy of Sciences, Laboratory of Carbohydrates, Moscow, Russia 117997 section and have been removed from the Discussion section beneath the Fig. 9 caption.

The original article has been updated.

Publisher's Note Springer Nature remains neutral with regard to jurisdictional claims in published maps and institutional affiliations.
4 National Medical Research Center for Obstetrics, Gynecology and Perinatology Named After Academician V.I. Kulakov of the Ministry of Healthcare of the Russian Federation, Moscow, Russia

5 School of Chemistry, National University of Ireland, Galway, Ireland

6 Institut für Anatomie, Histologie und Embryologie, Tierärztliche Fakultät, Ludwig-Maximilians-Universität München, 80539 München, Germany

7 Centre for Kode Technology Innovation, School of Engineering, Computer \& Mathematical Sciences, Auckland University of Technology, Auckland 1010, New Zealand 